\title{
Research on Project-Driven Teaching Method of Technology of Mechanical Manufacture Based on Ability Training
}

\author{
Changhe Li, Yali Hou, and Jianjun Yang
}

\begin{abstract}
Technology of Mechanical Manufacture has the characteristics of high comprehensiveness, strong theoretical property as well as strong practicality and applicability. However, traditional teaching mode has many disadvantages, such as excessive teaching contents, "ambiguity between primary and secondary knowledge", which do not conform to the characteristics of the curriculum. The project-driven teaching method which is student-oriented and teacher-guided could integrate boring knowledge teaching into vivid experiment and design. This is conducive to training students' innovation capability, team spirit and comprehensive quality and could arouse students' enthusiasm for learning. This paper elaborated the general idea and contents of the project-driven teaching method, as well as the specific method and steps of it. Technology of Mechanical Manufacture is the last teaching program of Mechanical Manufacturing and Automation before graduation thesis. It aims to train students' ability to analyze and solve practical problems with learned basic theories and practical knowledge, and ability to use mechanical design standards and norms. Through such project-driven teaching method, students cannot only make self-investigation from the perspective of engineers, but also integrate learned knowledge in project practices, shift the original cognitive and perceptive comprehension to practical comprehension, and enhance training in practical ability. Students can integrate learning and practice and train their own comprehensive ability through project design, organization, implementation and evaluation.
\end{abstract}

Index Terms-Project-driven teaching method, Technology of Mechanical Manufacture, ability training, innovation capability, higher education.

\section{ORIENTATION OF THE CURRICULUM INTRODUCTION}

Technology of Mechanical Manufacture is the main compulsory course of Mechanical Engineering in institutions of higher education, which plays an important role in compulsory curriculum system. The course contents have three characteristics. The first characteristic is high comprehensiveness. It involves related contents of many subjects, such as Mechanical Graphing, Metallurgical Technology, Theory of Metal Cutting and Cutters, Metal-cutting Machine Tool, etc. It covers abundant knowledge systems and many problems are taught based on these subjects. The second characteristic is strong theoretical property. It mainly deals with general problems in part

Manuscript received February 9, 2016; revised April 20, 2016. This research was financially supported by the project of teaching reform in colleges and universities in Shandong Province (2012042)

The authors are with School of Mechanical Engineering, Qingdao Technological University, Qingdao, China (e-mail: sy_lichanghe@163.com, houyalichina@163.com,yjjdem@163.com). processing crafts and product assembly technology, including analysis and theory of processing craft. It requires students to be able to design mechanical process technologies and procedures accurately for different parts, and compile the assembly technological procedure correctly. Students are asked to master a lot of basic concepts, principles and skills. The third characteristic is the strong practicality and applicability. It emphasizes on teaching process and method of part processing from workblank to acceptable product, enhancing students' ability in theoretical study of technologies, technological design as well as discussion and application of advanced manufacturing technology, and training students' innovation capability in problem analysis and solving. Key attentions are paid to train students' ability to solve practical problems. Therefore, the overall teaching object of Technology of Mechanical Manufacture is to train integrated advantaged talents for engineering technology and independent innovation for the modern manufacturing industry. It focuses on training students' ability to understand and use basic knowledge, skills and practices of mechanical manufacturing. Such characteristics and teaching objective of Technology of Mechanical Manufacture determine the necessity to break the traditional teaching method and establish a new one which targets at ability training and orients to process procedures [1]. This teaching method centers on practical project teaching and carries out learning activities related to projects.

\section{EXISTING PROBLEMS AND CAUSES OF THE CURRICULUM MODEL}

Technology of Mechanical Manufacture involves quality assurance, productivity and economic issues in mechanical processing of parts and product assembly. Craft is the most active factor of production. It is not only a concept, but also a real method and mean which practiced in the process system composed of workpiece, cutter, machine tools and jig. Technology of Mechanical Manufacture covers an extensive knowledge scope. It needs support of various subjects and is closely related to actual production. Traditional teaching mode has many disadvantages, such as excessive teaching contents, "ambiguity between primary and secondary knowledge", unsatisfying teaching effect, heavy classroom teaching load, students' poor understanding on relationships of different chapters, no qualitative improvement on understanding and use of knowledge points and bad practical application ability. These are mainly caused by the following aspects. 


\section{A. Students Only Learn What Teachers Taught}

Existing teaching method adopts classroom teaching and almost passive listening of students. Students have no definite learning goal, but are passive to acquire knowledge. They only learn what teachers taught. Such "cramming education" fails to highlight keys of the subject and students feel powerless to solve practical problems with learning knowledge although they perform well in school examines.

Technology of Mechanical Manufacture has complicated contents, but poor systematic structure. Although students have comprehended single principles and method and are good at dealing with single-aspect homework and examines, they are difficult to analyze the whole complicated and comprehensive technological problem by combining many knowledge points [2]. In fact, they lack a distinct and complete concept, so they couldn't understand objective and use of every part profoundly. As a result, they are difficult to combine different knowledge points during comprehensive application.

\section{B. Students Haven't Established a Complete Concept of Processing Technology in the Practice and They Have Forgotten the Processing Scene}

Due to the strong practicality, Technology of Mechanical Manufacture requires good knowledge on production practice. The most primary thing is to have a vision of field processing, that is, spatial processing relation among workpiece, cutter, machine tool and jig, including the working motion and relative positions of different components. Metalworking practice is only one practice before the Technology of Mechanical Manufacture. However, students haven't established a complete concept of processing technology in the practice and they have forgotten the processing scene. Therefore, many processing problems couldn't be analyzed and solved accurately.

There are many teaching methods, for example, PBL (Problem-Based Learning), TBL (Team-Based Learning) and CBE (Competency-Based Learning) [3]. PBL is a problem oriented, student centered education, emphasizing the skills of students to solve the problem and the ability of autonomous learning. TBL emphasizes students' cognitive ability, team work spirit and interpersonal skills. CBE emphasizes job requirements and the main role of students in the learning process, students are responsible for their own learning, teachers are just learning process managers.

The project-driven teaching method which is student-oriented and teacher-guided could integrate boring knowledge teaching into vivid experiment and design. This is conducive to training students' innovation capability, team spirit and comprehensive quality and could arouse students' enthusiasm for learning.

Project-driven teaching method teaches knowledge through "projects". To make students be used to solve problems completely, the preset "projects" contain knowledge of many subjects. With teachers' guidance, it asks students to handle an independent project, including information acquisition, program design, implementation and final evaluation. In this way, students understand and comprehend basic requirements of the whole process and every links.Students trained by the project-driven teaching method meet comprehensive requirements on knowledge, capability and quality to advanced manufacturing talents. The project-driven teaching method could increase employment of students effectively and reflect the purpose of education serving the society better.

\section{IMPLEMENTATION OF PROJECT-DRIVEN TEACHING METHOd In TECHNOLOGY OF MECHANICAL MANUFACTURE}

The main characteristic of project-driven teaching method is emphasis on group cooperation and independent implementation. Project implementation has definite time, specific content, method and evaluation standard. In project-driven teaching method, students understand problems or tasks that have to be solved or accomplished, set project discussion and learning group, determine a team leader and requirements on labor division and cooperation, look up information, and put forward basic knowledge and skills of the curriculum. This improves students' ability in problem analysis and solving, independent study, though expression and team cooperation. By limiting time to complete required tasks, students ' ability to arrange time can be trained. By setting the learning group, responsible person and members work in cooperation with a due division of labour, you can exercise their interpersonal communication and management ability of students. Through access to information to analyze and solve problems, you can exercise students' ability of independent thinking. Using the accumulated knowledge to explore and research in the brain to create a new thinking, you can train students' pioneering and innovative ability. Thus, the project-driven teaching method aims at training students' comprehensive ability. This is a teaching mode which targets at ability training, orients to processing, and integrates theoretical teaching and project-based practical teaching organically. Centering on practical project teaching, it organizes and teaches elaborately prepared projects. It also attempts to create a "real" field processing scene or environment for students [4], thus enabling to enhance their ability concerning problem solving, team spirit and thinking. Since students are learning basic knowledge and developing mutual learning skills, this project-driven teaching method extends some knowledge and thinking in theoretical teaching. It is necessary to design some topics students are interested in and train their abilities. Students are asked to make essential preparations according to pre-assigned topics, including analysis, comparison and usage as well as proposing feasible solutions.

\section{A. General Idea}

The project-driven teaching method breaks constraints of traditional classroom teaching and introduces a series of team practices of projects related to the teaching content. Following the course schedule, students learn theoretical knowledge and practice projects in limited classroom time and spare time, so they can learn things in practices and apply learned knowledge in practical engineering. This turns passive learning into positive learning. Thus, the project-driven teaching method accords with the characteristics of Technology of Mechanical Manufacture, 
namely high comprehensiveness, strong theoretical property as well as strong practicality and applicability. This makes project-driven teaching method results better learning outcomes in technology of mechanical Manufacture subject. Through such project-driven teaching method, students cannot only make self-investigation from the perspective of engineers, but also integrate learned knowledge in project practices, shift the original cognitive and perceptive comprehension to practical comprehension, and enhance training of practical ability. Students can integrate learning and practice and train their own comprehensive ability through project design, organization, implementation and evaluation.

\section{B. Contents of the Project-Driven Teaching Method}

In the project-driven teaching method of Technology of Mechanical Manufacture, a series of processing projects of different parts are established and students are divided into teams according to the overall workload of the project [5]. In view of the course schedule, students learn theoretical knowledge and design specific part processing program simultaneously in little classroom time (mainly for team discussion and collective counseling of difficulties) and abundant spare time according to predetermined examining points. Specific project contents are formed according to different structures of parts. A "virtual" processing scene is set up by combining processing instruments in internship factory and laboratory. Finally, the technique implementation procedures and specific processing of the project are accomplished.

It classifies knowledge points of different chapters of Technology of Mechanical Manufacture and constructs several specific projects by combining with the teaching objective. Every project is led by specific tasks and supported by several knowledge points and small tasks. Finally, it establishes a complete practical project-based teaching system. Project size, difficulty and teaching requirements shall conform to actual knowledge and ability of students. Project may be either design type or comprehensive type. During project organization, attentions shall be paid to the role relationship between the teacher and students. In project-driven teaching, students are the subject, while teacher is only responsible for organizing, coordinating, assisting, serving and monitoring the project implementation [6]. After the project is determined, the teacher shall organize related theoretical knowledge, carefully predict problems that may occur, provide related reference information and channel of information acquisition, prepare necessary hardware and software, form corresponding teams and organize students for project design and implementation.

Specific method and steps are introduced in the following text.

1) Formation of project teams: Formation of project teams is the foundation of smooth implementation. Project team consists 4 5 students, which is determined by the teacher according to project size and difficulty. Generally, students are divided according to the list, which makes students learn to obey the arrangement. Each team has one leader which is voted by members.

2) Project preparation: Project preparation is the prerequisite of smooth implementation. According to the teaching objective, adequate quantity of part drawings with certain technological characteristics is chosen and allocated to different teams in advance. During the whole teaching process, every knowledge point (or chapter) requires students to analyze the part or a specific processing procedure and propose related problems.

3) Determination of project theme and planning: In the middle of the course teaching, students shall integrate teaching contents and summarized problems to determine the project theme. They are asked to make project plans (including implementation time, contents and method) and decompose the project into several small tasks to every member of the team.

4) Project implementation: After finishing project preparation, every student shall carry out the assigned small task. During this period, the teacher is in charge of solving occurred problems, offer corresponding assistances and supervising the project implementation.

5) Analysis and report: To realize expected teaching objective, teams shall make regular analysis and discussion on results of decomposed small tasks. The next project plan can only be allocated after an agreement is reached.

6) Report writing: Each team shall write a project team based on analysis and discussion after accomplishing the project.

7) Assessment and feedback: Each team shall make PPT report after accomplishing the project and the teacher will evaluate the project performance and quality. This is beneficial to improve project performance in future project-driven teaching.

This project includes technology making, positioning analysis, jig structural design and physical manufacture. Main contents are:

1) Formulate machining process technological procedure of $x \times$ part (team cooperation)

Determine workblank category, positioning basis and surface processing method, processing sequence and intensity as well as technological equipments.

Calculate finishing allowance, procedure size and tolerance as well as cutting specifications and norm of working hours.

Requirements: Ensure machining quality and satisfying productivity of the $\times \times$ part. Make sure the project plan is feasible.

Submit: process sheet and operation sheet shall be filled in after the optimal project plan is determined.

2) Design of special jig for the $x$ procedure of $x \times$ part processing (one problem for the lifetime, no repeat)

Determine location o this special jig, toll setting device and clamp program. Draw a structural draft and calculate positioning error, clamp force and power plant. Determine sizes of the main structures. Draw the official assembly map of the jig structure (the workpiece is clamped tightly, labeled with related size and tolerance and fits, filling the part list and technical specifications).

Requirements: reasonable positioning, reliable fixing and easy operation; try to apply flexible multi-parts clamp; design map shall conform to the national standard and mechanical drawing norms. 
Submit: draw a complete jig assembly map (2D, 1:1, A0/A1).

3) Virtual assembly of special jig (one problem for the lifetime, no repeat)

According to the official jig structure map, 3D map of parts is drawn. Virtual assembly of the 3D jig model is accomplished and the assembly process is displayed dynamically.

Submit: draw a 3D jig model.

4) Actual manufacturing of the special jig (team cooperation)

Based on the official jig structure map, graphs of all parts are drawn and the technological procedure is compiled according to single-workpiece processing type. Machining and physical assembly are implemented in the laboratory and engineering training center.

Submit: physics and pictures of the complete special jig.

5) Writing Design Instruction and PPT report

The Design Instruction is a comprehensive summary on abovementioned analysis, calculation and design. It requires perfect statements and clear graphs, conforming to the national standards and related standards issued by special departments as well as Chinese grammatical norms. Related calculations shall have formulas and process and sources of listed data shall be pointed out. PPT is for final defence.

Requirements: Please refer to the Curriculum Design Rules for requirements on contents and format.

Submit: Paper Design Instruction and electronic edition of PPT.

\section{INNOVATIONS, EXPECTED EFFECT AND ACTUAL ACHIEVEMENTS}

Technology of Mechanical Manufacture is the last teaching program of Mechanical Manufacturing and Automation before graduation thesis. It aims to train students' ability to analyze and solve practical problems with learned basic theories and practical knowledge, and ability t use mechanical design standards and norms. After finished this course, students are asked to design a typical moderate complicated part machining technological procedure and corresponding jig.

This program takes the typical part machining as the principal line and develops a complete knowledge chain for Mechanical Manufacturing and Automation [7], thus strengthening existing teaching effectiveness and practices and highlighting features of the major. It lays foundations for graduation thesis and employment.

\section{A. Expected Effect}

1) Reinforce understanding on relationships of Technology of Mechanical Manufacture, Cutting Theory and Cutters, Machinery Manufacturing Equipments as well as their effects in practical production. Understand the whole machining process.

2) Grasp basic approaches of information retrieval, data inquiry and information acquisition based on modern information technology. Be proficient in using design information, such as manual and graphs.

3) Train ability of combining theory and practice. Use learned knowledge to design actual machining technology procedures and related jig. Develop certain ability to analyze and solve engineering problems.

4) Exercise ability of structural design and practical ability.

5) Cultivate students' sense of responsibility and professional ethic, certain organization and management ability, strong ability of expression, communication skills, team collaboration and competition.

\section{B. Relation to Knowledge Points}

1) Determination of machining technological procedures involves theoretical knowledge of many subjects (e.g. Technology of Mechanical Manufacture, Cutting Theory and Cutters, Machinery Manufacturing Equipments, CNC Technology and Application, Non-traditional Machining) and practical knowledge.

2) $2 \mathrm{D} / 3 \mathrm{D}$ design of the clip: it involves Mechanical CAD/CAM, Interchangeability Principle and Measurement, Mechanical Design, and Mechanics of Materials as well as practical knowledge.

3) Manufacture of special jig: perceptual knowledge, basic operating skills and manipulative ability.

\section{Explore Teaching Mode Integrating Classroom Teaching, Discussion and Self-study}

Classroom teaching content must be simple and students shall take notes. The Introduction plays the decisive role in teaching Technology of Mechanical Manufacture, which could guide the course learning. The Introduction describes research objects and contents of the curriculum and helps students to have a perceptual understanding on the curriculum system and contents. It 1) reduces blindness of learning; 2) introduces characteristics, learning method, requirements and regulations; 3) introduces basic concepts and principles of machining to students intuitively through case studies, which dissipates students' fear of new subjects; 4) introduces development history of the subject and its big contributions to social changes, and helps students to be aware of its importance; 5) elaborates current situations of machining industry and advanced manufacturing technologies and technological levels in China and foreign countries, and enhances students' sense of mission, responsibility and learning enthusiasm. Students will gain a clear understanding of the whole curriculum and the overall teaching objective through the Introduction. Each chapter shall point out the explicit teaching objective, ability training and key contents. Furthermore, involved important concepts (not only the simple introduction of concepts), problems that have to consider during study and thinking method shall be explained. These are important things that won't be available in textbooks and could teach students how to learn the course. The teacher will give lectures on key knowledge points which students are difficult to understand, but only offer necessary counseling to students for easy and common knowledge or some graphs. Through mutual discussion, students will master important contents which could be deduced or inferred with learned knowledge or taught knowledge.

"Discussion" cannot only investigate knowledge depth and breadth of students, but also test students' innovative thinking ability and problem analysis ability from the perspective of 
individualized development. Additionally, it is a communication channel between teachers and students. Through discussions, teachers will discover students' bias knowledge comprehension and could correct it timely, thus further improving the teaching effect.

\section{Advantages of Multimedia Teaching Shall Be Used Thoroughly to Make the Teaching Process Intuitive and Acceptable by Students}

With the deepening of educational reform, the conflict between teaching content and credit hours intensifies more and more. To accomplish teaching contents with fewer credit hours, despite of brief presentation, modern teaching method shall be applied to make teaching contents intuitive. Considering the strong practicality and comprehensiveness of Technology of Mechanical Manufacture, attentions shall be paid to combine with the actual production. Difficult contents shall be represented vividly by using lantern slides, videos and computer graphics and animation, which could enhance students' perceptual understanding. For example, when describing basic concepts in Machinery Manufacturing Overview, students master the machine production process intuitively through video watching. The machine production process includes preparation of production technologies (e.g. product design, production preparation and raw material transportation and storage), workblank manufacturing, machining and heat treatment, assembly and debugging, and production service process (e.g. test and trial run, painting and package). The production process is actually a process to change raw materials (or semi-finished products) into products. Difficult and confusing concepts about procedures, steps, feed, installation and station are taught by watching videos about turning and drilling, which are intuitive and easy to be accepted by students.

Based on theoretical teaching that combines with internship factory and training bases and enterprise communications, it discovers that practical teaching of engineering courses is hardly accepted. In the past, Technology of Mechanical Manufacture was taught in classroom only. Although some contents like influences of turning and grinding errors on workpiece quality were introduced thoroughly, students are still difficult to understand them completely. They feel such influences abstract and impractical. Combining with production internship and metalworking practice in school, machining contents (e.g. turning and grinding) are taught in internship factories. Students operate under the guidance of teachers, observe machining process and workpiece quality, and analyze defect causes. In this way, students gain practical understanding on theories, a perceptual understanding on related parameters and experiences, and deeper understanding on hardness of grinding wheel grains, cutting performance as well as surface quality. Besides, structures of planing and milling tools are introduced in internship factories or training bases. Meanwhile, field operation of workers is combined with demonstration teaching, so students are easy to understand technologies characteristics, application scope, working contents, operational security and precautions of different machining tools. This not only makes knowledge easy to be understood, but also trains students' learning interest and application ability. The project-driven teaching method achieves good teaching effect.

\section{APPLICATION SCOPE AND VALUES}

Students learn and master materials for mechanical engineering, mechanical drawing, mechanical principles, heat treatment of materials, manufacturing technologies, as well as usage and operation knowledge of different machine tools through project design (including 3D modeling, 2D graph design and animated simulation), part processing, product assembly and product quality test. This teaching method fully develops creativity potential of students and trains students' thinking and abilities, including practical ability, operational ability, analytical ability, response ability, communication skills, cooperation capability and comprehensive ability of actual problem solving. It is expected to be an outstanding example and leader in the future.

\section{REFERENCES}

[1] Y. L. Hou and C. H. Li, "The research and practice on the integrated optimization of the machinery manufacturing joint curriculum group platform," Advances in Social and Behavioral Sciences, vol. 6, pp. $10-16,2014$

[2] R. F. Wang, "Combination of traditional teaching and interactive teaching," The Border Economy and Culture, vol. 12, pp. 63-72, 2011.

[3] C. H. Li, Y. L. Hou, J. J. Yang, and H. B. Lan, "The construction of practical teaching system and innovative talent training mode in the fundamental course of mechanic manufacturing," Advances in Education Research, vol. 54, pp. 7-12, 2014.

[4] P. Różewski and O. Zaikin, "Integrated mathematical model of competence-based learning-teaching process," Bulletin of the Polish Academy of Sciences Technical Sciences, vol. 63, pp. 245-259, 2015.

[5] F. Peng, F. X. Xiao, and Y. L. Wang, "Improving experiment examination method and cultivating innovative talents," The Journal of Science and Education, vol. 12, p. 192, 2008.

[6] L. P. Gu, "Practical teaching system construction in higher vocational colleges," China's Higher Education Research, vol. 11, pp. 67-68, 2005 .

[7] J. Jiang, "Mechanical manufacturing basis curriculum project teaching method in the exploration and practice," Journal of Anhui Technical College of Electrical Engineering, vol. 4, pp. 95-98, 2005.

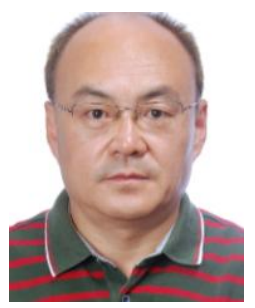

Changhe Li was awarded his $\mathrm{PhD}$ from the Northeastern University, China in 2006. He is currently a professor at the School of Mechanical Engineering of Qingdao Technological University. His research interests include computer applications in the study of surface finish mechanism; materials removal rate; abrasive finishing; quick-point grinding; surface roughness and integrity; $\mathrm{CNC}$ grinding; superabrasive grinding wheels; grinding temperature field modelling; simulation of grinding processes; minimum quantity lubrication (MQL) grinding and high speed machining. 